Kudryavtsev O.A., Zhikharev M.V., Olivenko N.A. Creation and verification of computational models for analysis of the mechanical behaviour of jet engines composite components under high-velocity impact: main problems and basic recommendations. PNRPU Mechanics Bulletin, 2019, no. 4, pp. 68-79. DOI: 10.15593/perm.mech/2019.4.07

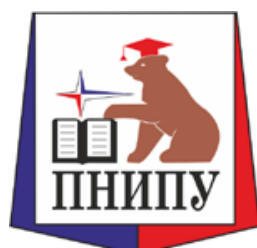

ВЕСТНИК ПНИПУ. МЕХАНИКА

№ 4, 2019

PNRPU MECHANICS BULLETIN

http://vestnik.pstu.ru/mechanics/about/inf/

DOI: 10.15593/perm.mech/2019.4.07

УДК 539.3

\title{
CREATION AND VERIFICATION OF COMPUTATIONAL MODELS FOR ANALYSIS OF THE MECHANICAL BEHAVIOUR OF JET ENGINES COMPOSITE COMPONENTS UNDER HIGH-VELOCITY IMPACT: MAIN PROBLEMS AND BASIC RECOMMENDATIONS
}

\section{O.A. Kudryavtsev*, M.V. Zhikharev, N.A. Olivenko}

South Ural State University, Chelyabinsk, Russian Federation

\section{O CTATbE}

Received: 11 March 2019

Accepted: 01 November 2019

Published: 30 December 2019

\section{Ключевые слова:}

jet engine, fibre reinforced plastic, ballistic impact, numerical simulation, mesoscale model, model verification.

\begin{abstract}
АННОТАЦИЯ
Currently, modern CAE programs like ANSYS, LS-DYNA, ABAQUS, Simcenter 3D etc. are widely used to develop each engineering product. CAE reduces development costs and speeds up product launches. Computer modelling allows eliminating unsuccessful design options at early design stages and minimising or eliminating critical design changes at the prototype testing stage. Computer simulations are especially needed for the development of high-performance perfection designs like jet engines. The use of composites in the engines requires the availability of appropriate design tools to assess the mechanical behaviour of structural elements made of such materials under operational loads and in an emergency. Predictive modelling of the deformation and fracture of the composite fan blades and fan case subjected to dynamic loading cause considerable interest of engineers. As in the case of simulation of shock loading of metals, a model of a composite material must be verified. However, the problem is that the fibrous composite material itself is already a structure and can be modelled in various ways: without considering the layered structure (homogeneous approach) taking the mesostructure into account (at the ply-level or at the yarn-level) taking the microstructure into account (at the filament level). The requirements for the initial data, the number of parameters determined during the verification process, the complexity of creating geometric models will differ in each case. This paper briefly describes the main approaches to the numerical simulation of composite elements under highvelocity impact loading. The main advantages and disadvantages of these approaches are also considered. On the example of the meso-scale approach, the main parameters of the computational models that affect the results of calculations are shown. Based on the obtained data, the main recommendations were formulated on the validation of meso-scale models of composites.
\end{abstract}




\section{Introduction}

Jet engines are some of the most complicated technologies on the planet, and they must have outstanding reliability and comply with the modern requirements for weight, noise and other things. Today, it is impossible to create a competitive jet engine without using components made of fibre-reinforced polymers (FRPs) [1-3].

Design of high-loaded parts of jet engines made of fibre-reinforced plastic is a complex problem that requires not only development of new materials and technologies, but also creating of appropriate computational tools for analysis of strength, durability and reliability of these composite parts under working loads and during an emergency.

Nowadays, software packages that use finite element method (FEM), such as ANSYS, LS-DYNA, ABAQUS, Simcenter 3D are widely used for mechanical behaviour analysis of FRP parts under different loading conditions. A series of articles [4-6] on the development of methods of stress-strain state and strength analysis of CFRP outlet straightener blade for new turbofan engine PD-14 under quasi-static loading is one of the first examples of using numerical methods for designing of load-bearing composite elements in Russian aircraft engine building. A significant amount of work related to the increasing the amount of composite materials in the perspective turbofan engines PD14 and PD-35 is performed today, and the most important task for engineers is to create a composite fan blade and a fan case for them. To solve this problem, ensuring not only static but also cyclic and impact strength of these parts is needed. The developers of aircraft engines try to minimise the number of tests of full-size structures due to their high complexity and high cost. In this regard, great attention is paid to numerical simulations.

Numerical models for the analysis of deformation and fracture of composite elements during high-velocity impact are especially needed for full-scale simulations of turbofan engines with composite fan cases and blades during fan blade out and bird strike events. These computational models must satisfy the following requirements: a high numerical efficiency, a possibility to predict the deformation and fracture of FRP parts correctly and an accuracy in assessment of the amount of energy absorbed by the material in a wide range of the projectile velocities [2]. Meeting these requirements is provided by selecting an appropriate approach to composite structure modelling and sufficient computational and experimental verification of the models. It is important to note that there are lots of problems and difficulties at the stages of creation and verification of computational models.

The main goal of this study was to find a suitable approach for the modelling of the high-velocity impact loading of large size FRP parts and consider the main problems arising from its application. The article structure is as follows: Section 2 contains a brief review of existing modelling approaches for analysis of mechanical behaviour of fibre-reinforced composites subjected to high-velocity im- pact with a discussion of their advantages and limitations. An example of a meso-scale approach application for numerical simulation of CFRP plate subjected to impact loading will be presented in Section 3. The obtained results of numerical simulations and their discussion are described in Section 4. Section 5 gives a conclusion.

\section{Current and prospective approaches for simulations of the damage and failure of composite materials subjected to high-velocity impact}

First, it is necessary to separate the concepts of "computational model" and "material model". A computational model is a set of geometrical and mesh models of FRPs, material deformation and fracture models.

The classification of the FRPs modelling approaches by depending on the detail of the geometric model is the most popular. Three approaches are used for applied calculations in practice (Fig. 1): macro-scale (lamina-level), meso-scale (ply/yarn-level) micro-scale (filament-level). Consider each of the approaches in more detail.

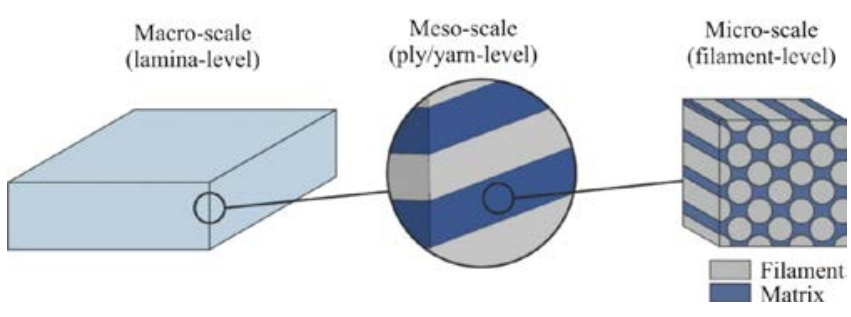

Fig. 1. Modelling scales for analysis of the FRPs mechanical behaviour

\subsection{Macro-scale (Lamina level)}

The macro-scale approach for simulation polymer composite materials is based on the use of classical laminated plate theory (CLPT) [7]. The composite material is simulated as a continuous homogeneous medium with orthotropic or anisotropic properties without explicit consideration of the layered structure. The heterogeneity of the mechanical properties in the thickness of the material is taken into account using special finite elements. Each layer in the real material corresponds to the integration point in the element with appropriate stiffness matrix. Standard pre-processors of various software packages, as well as specific software, for example, Fibersim [8], can be used to create computational models. The apparent advantage of this approach is the high numerical efficiency.

The macro-level approach became the most widely used in the analysis of static strength of composite material structures. However, to simulate the deformation and fracture of composite parts and structures under the high-velocity impact, this approach in its pure form does not quite fit, since it does not allow taking into account material delamination. Several works may be noted [9-15], wherein the authors used a macro-scale approach in the simulation of impact 
loading of composite panels. The presented computational models allowed predicting the amount of absorbed energy with sufficient accuracy, but they did not provide a reasonable agreement between the computed and experimental fracture patterns. Also, there are difficulties with determining the parameters of the material model, which can be more than 30 and some of them can be selected only by calculation using the cut-and-try method.

\subsection{Meso-scale (Ply/Yarn level)}

The meso-scale (ply/yarn-level) approach can be considered as a logical development of the macro-scale approach since the material layers/reinforcing yarns are still simulated as a continuous medium with orthotropic properties, but additional interface layers between layers/matrix material are also explicitly modelled. Fracture of these elements allows taking into account the composite delamination.

There possible ways for interface layers modelling are as follows: cohesive elements with the corresponding material model (CZM); special contacts (tiebreak/breakable); common 3D elements with the corresponding material model.

Hundreds of papers have been published, wherein the authors used cohesive elements in ply-level simulations of FRP impact loading [16-24]. This approach is quite effective and allows using both shell and solid elements in calculations.

The use of cohesive elements involves two significant problems:

1. Sensitivity to the size of the finite elements (FE) mesh [25]. For an appropriate simulation of delamination using cohesive elements, it is necessary to have at least 3-4 elements in the crack-opening zone. Otherwise, it is necessary to adjust the properties defined experimentally for a particular mesh size in the computational model.

2. The results of static tests are used in a majority of cases to determine the parameters of the cohesive elements deformation model. The most popular tests are doublecantilever beam test and bending specimens with defects [26]. Then, it is necessary to introduce corrections for high strain rates, FE size etc.

These problems are not an indicator that the use of cohesive elements is ineffective, or it gives false results. They are a signal to calibrate the computational model for specific tasks based on experimental results that are close to the simulated ones with a particular FE size.

The second popular option in the meso-scale simulation of FRPs is the using of special contacts. For instance, in LSDYNA software, the user can choose from several types of contacts formulations, including close to cohesive ones (OPTION=9). This approach is also one of the most popular in the simulation of delamination in composite structures subjected to impact loading [27-31].

The use of breakable contacts in the simulation is associated with the same difficulties as the use of cohesive elements: sensitivity to the FE size and the need to verify the parameters of the computational model based on dynamic tests data. In the case of dynamic loading, the efficiency of the use of cohesive elements and breakable contacts is almost identical [32]. Both approaches make it possible to obtain desirable results when there is enough experimental data for model verification.

The third option is based on the using of standard threedimensional elements that are used to simulate interface layers. Often this approach is used along with yarn-level models [33-35], but other options are possible [34]. The explicit matrix consideration in the simulation allows reducing the number of parameters in the model that require identification since it is possible to use simple material deformation models (linear elastic or elastic-plastic). The yarnlevel approach or its combinations with ply-level one [36$41]$ is more often used to simulate 3D-reinforced composites under impact loading.

The disadvantages of meso-scale approach include the increased (compared to the homogeneous approach) difficulties of the geometry and FE mesh creation and high computational cost. Impact tests and corresponding calculations are also required for verification of computational models.

\subsection{Micro-scale (Fibre level)}

The use of micro-scale approach needs considerable attention to the accuracy of the composite microstructure accounting [42]. For example, Segala and Cavallaro [43] conducted studies on the impact loading of the composite based on UHMWPE applying filament-level.

Micro-scale approach in its pure form is rarely used for practical calculations since the models' computational cost and complexity in case large components will be enormous. A more common practice is the use of micro-scale simulation to obtain the integral properties of the composite layer for further macro-scale modelling [44].

\subsection{Prospective approaches for simulations of large size FRP components}

The given data suggest that simulations at the ply-level are the most commonly used to analyse the impact loading of structural FRPs. With a proper verification of the computational model, this approach allows obtaining an accurate assessment of the absorbed energy and the fracture pattern. At the same time, the use of this approach is associated with a computational cost increasing. This disadvantage becomes critical when modelling large parts. In this case, a combined approach can be very useful.

The combined approach is a compromise between the dimensionality of the problem and the desire to obtain calculation results close to the experimental one. A layered geometric model is used in the impact zone and around it, but a homogenous approach is used in areas far from the impact site [45-47]. The connection of the model parts with different discretisation can be made in two main ways: 
shared nodes or specialised contact algorithms. Since there are only few works on this topic, there is not enough data about the advantages and disadvantages of both methods.

Thus, meso-scale and combined approaches are the most prospective for simulation large-size FRP elements under impact loading. At the same time, to use the combined approach, it is necessary to have a working mesoscale computational model.

In the next two sections, the features of simulation structural composites at the ply-level with the use of breakable contacts are considered on the example of CFRP plate.

\section{Using of ply-level approach for numerical simulation of CFRP plate subjected to impact loading}

Computational studies of ballistic impact loading of the composite element were conducted to analyse the features of the meso-scale approach. The experimental results of ballistic impact testing of GFRP plates [48] were used for the validation of numerical models.

In addition to computational studies, the following topics were shortly discussed: the main mechanisms of energy dissipation that must be taken into account in the developed models, the influence of the high strain rates the CFRP mechanical properties.

\subsection{Main energy absorption mechanisms in composites during high-velocity impact}

The creation of effective numerical models for impact simulations requires an understanding of the primary energy dissipation mechanisms in composites during such loading. Consider some of the most cited papers where the authors studied the mechanisms of energy dissipation in composites under high-velocity impact loading.

Morya et al. [49] conducted studies of the composites based on nylon, aramid, and UHMWPE fibres subjected to a steel ball impact. The developed and verified the analytical model of the composite-projectile interaction showed that the main part of the kinetic energy of the impactor is dissipated through the fracture of the primary yarns, elastic deformation of the composite and due to the kinetic energy transferred to the composite panel.

Naik et al. (Indian Institute of Technology Bombay) published some work [50-57] with results of experimental and analytical studies of mechanical behaviour of CFRP, GFRP and hybrid composites under the high-velocity impact. The analytical model developed by the authors was quite similar with the model presented by Morya et al. The differences were in the accounting of the inhomogeneity of the deformations distribution in the composite fibres through the thickness, considering the additional mechanism of energy dissipation - shear plugging. During the researches, the authors found that the greatest amount of energy of a high-velocity projectile is dissipated by shear plugging, the acceleration of panel and fracture of the primary yarns.
Similar results were obtained in [58] using numerical and analytical modelling and in [59] with the help of another analytical model. At the same time, in all these works, it was noted that the prevalence of one or another mechanism depends on the projectile velocity and geometry, composite thickness, material mechanical properties etc.

It should be noted that the shear plugging fracture is typical for sufficiently thick composites and flat-end impactor. In the case of a spherical projectile, this phenomenon does not occur, that is confirmed by the results obtained in [48, 60-62]. Moreover, in [58, 59] authors showed that for thin composites, the contribution of energy dissipated by shear plugging into the overall balance is negligible. Based on the results of [58-62], it can be assumed that in the perforation of thick composites by flat-end impactors the main mechanism of energy dissipation is also the rupture of fibres due to their tension and bending, but not from the shear. A perforation scheme of the composite (Fig. 2) illustrates that. In the case of a flat-end projectile, the bending stress in the fibres near the point of contact is significantly higher than in the case of a spherical or ogival projectile, and it leads to pseudo-shear fracture.

If this hypothesis is taken as a working one, it will mean that it is necessary to know and take into account the composite shear in the transversal direction for using of homogeneous approach. When using the meso-scale approach (consideration of the layered structure of the composite), the properties of the material in the plane are much more critical. Conclusions about the reliability of this hypothesis can be done only after the relevant computational studies.
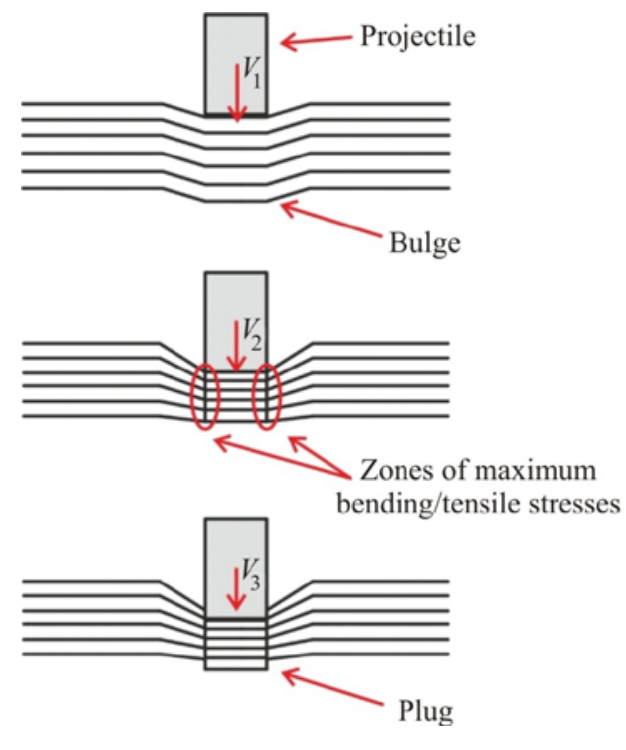

Fig. 2. Scheme of plug formation in the composite during high-velocity impact

Regarding the remaining energy dissipation mechanisms in FRPs, the authors of papers [49-59] agree that the amount of the projectile kinetic energy absorbed by matrix cracking, and delamination is negligible. With the thickening of the material and in the case of through perforation, the role of friction between the projectile and the composite target increases. 


\subsection{Influence of the strain rates on the CFRP mechanical properties}

Nowadays, in the scientific community, there is no consensus about the changes of the CFRP mechanical properties at high strain rates.

In work [63], the experimental data showed that the tensile strength of the material increased up to $55 \%$ with increasing strain rate, while the elastic modulus and the ultimate strain increased by up to $20 \%$ and $36 \%$ respectively. In another work [64], it was found that depending on the tensile strength and the strain rate is almost linear. The increase in tensile strength was in the range from $9 \%$ to $43 \%$. These results show significant changes in the properties of CFRP in comparison with other studies. For example, in [65-69], it was found that the tensile strength increased by $5-9 \%, 7 \%, 7.2 \%, 18 \%$ and $36 \%$ respectively. It should be noted that indirect methods are used to determine the properties of the composite at high strain rates in the vast majority of cases. This fact leads to an additional error in measurements. Also, the authors did not consider the physical reasons for increasing the characteristics of CFRP and carbon fibres.

In [70, 71], the authors concluded that the properties of carbon fibre bundles could be considered independent of the strain rate. In [72] the authors during the yarn-level simulations and experimental research founded that the changes of the 3D-reinforced composite properties were associated with a change in the fracture mechanism and the influence of dynamic effects, but not with a change in the properties of fibres. Studies of the properties of unidirectional CFRP confirm this fact too. In work [73], it was found that the modulus of elasticity and tensile strength of unidirectional CFRP in the longitudinal direction do not depend on the strain rate.

Based on the data of [70-73], it can be assumed that for CFRP based on fabrics (plain, twill, sateen etc.) changes in the integral properties at high rates will be the more significant, the higher the degree of curvature of the yarns. At the same time, the strength of the fabric-based composite will tend to the strength of the unidirectional composite with the same proportion of fibres in the direction of loading at high strain rates. This hypothesis requires additional confirmation.

It is important to note that the loading conditions and the strain rates during high-velocity impact differ significantly from those in tensile tests. It means that test dynamic tensile tests data can be used only as of the first approximation for the model and additional calibration using results of high-velocity experiments as needed. The work [74] is a good example of this.

\subsection{Description of the numerical models}

Numerical studies of CFRP plate impact loading were carried out to verify the findings of the literature review. A high-speed impact loading of a composite plate by a steel sphere is an initial boundary-value problem of the mechan- ics of a deformable solid. The principle of virtual work in a week form was used for the mathematical formulation of this problem:

$$
\int_{V} \sigma_{i j} \delta \varepsilon_{i j} d V=\int_{S} p_{i} \delta u_{i} d S-\int_{V} \rho \ddot{u}_{i} \delta u_{i} d V .
$$

Here, $\sigma_{i j}, \varepsilon_{i j}$ are components of elastic stresses and strains tensors, $u_{i}$ and $\ddot{u}_{i}$ are components of displacements and accelerations vectors, $p_{i}$ is a vector of surface forces, $\rho$ is a current density, $V$ is a volume of deformable solids, $S$ is an area subjected to surface forces. More details could be found in [75]. Numerical solution of equation (1) was carried out by the finite element method using LS-DYNA software with an explicit time integration scheme [76].

The ply-level approach was used in which the layered structure of the composite was considered explicitly. Calculation models were verified using experimental data published in [48]. The numerical models of the CFRP plates were created in LS-PrePost-4.5. All the computations were performed using the supercomputer «RSC Tornado SUSU» [77].

\subsubsection{Models geometry, boundary and initial conditions}

CFRP plates with a thickness of $4.67 \mathrm{~mm}$ based on a balanced fabric with lay-up $\left[0^{\circ}\right]_{24}$ and epoxy resin VSE1212 [48] were considered during numerical simulations.

In the geometry model, 24 layers of the real composite were replaced by 12 and 6 equivalent layers with thicknesses of $0.388 \mathrm{~mm}$ and $0.776 \mathrm{~mm}$ respectively to study the influence of the equal layers number on the simulations results. 8-nodes layered shell elements (ELEMENT_TSHELL) with ELFORM=5 formulation were used in all cases. Models with FE sizes of $2 \mathrm{~mm}, 3 \mathrm{~mm}$ and $4 \mathrm{~mm}$ (element edge length) were created to analyse mesh sensitivity of the model. One element was used through the thickness of equivalent layers. The interaction between the layers was taken into account by the contact algorithm discussed below. Figure 3 shows the mesh density and the number of equivalent plies for the all-using models.

The projectile was modelled using 8-nodes solid elements (ELFORM=1). Maximum element size for projectile discretisation was equal to the size of $\mathrm{FE}$ in the composite model.

Specimen size in the simulation had dimensions of $200 \mathrm{~mm} \times 245 \mathrm{~mm}$. The clamped part of the panel (55 $\mathrm{mm}$ ) was not considered in the calculations directly. Experimental boundary conditions [48] were taken into account by a prohibition of all nodes displacements and rotations at the lower part of the specimens (Fig. 4). Preliminary simulations showed that the difference in predictions between the model being used and the full specimen model was insignificant.

In accordance with [48], initial projectile velocities of $75.5 \mathrm{~m} / \mathrm{s}, 84.5 \mathrm{~m} / \mathrm{s}, 90.5 \mathrm{~m} / \mathrm{s}, 110.5 \mathrm{~m} / \mathrm{s}$ were considered during simulations for all mesh models. 


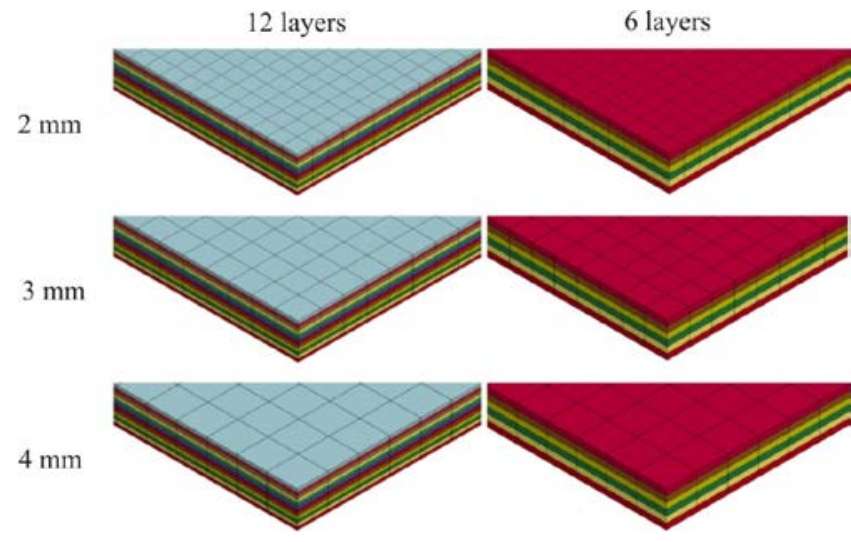

Fig. 3. The mesh density and the number of equivalent layers for all models
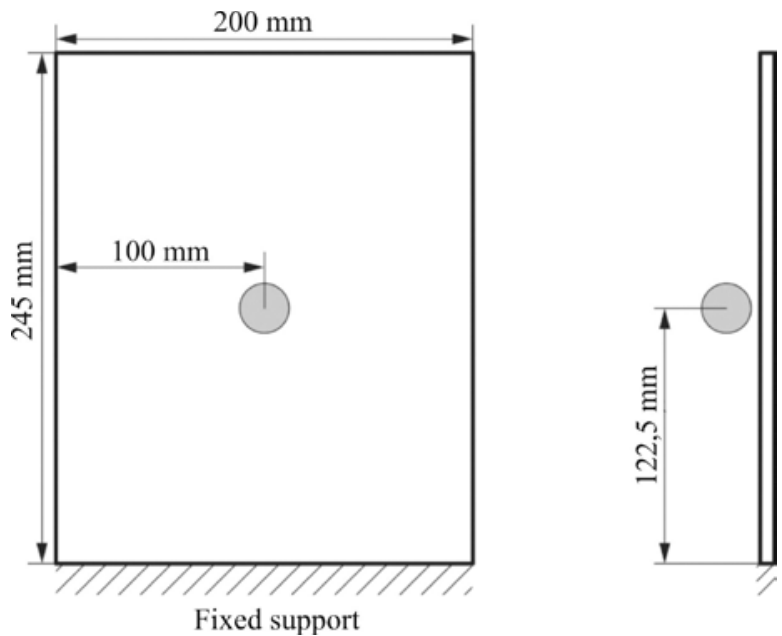

Fig. 4. Scheme of the composite plate loading in the simulations

\subsubsection{Material models and contacts}

Even though the authors of the work [48] did not provide any information about pre-preg, some signs (matrix type, the layer thickness of $0.19 \mathrm{~mm}$, weave type) indicate that VKY-39 was most likely used [78]. This pre-preg was developed by All-Russian Institute Of Aviation Materials (VIAM). Some mechanical properties of CFRP made of this pre-preg with using different technologies could be found in [4]. Mechanical properties of the VKY-39 layer are presented in Table 1. Material density was $1525 \mathrm{~kg} / \mathrm{m}^{3}$.

Table 1

CFRP layer mechanical properties [4]

\begin{tabular}{|c|c|c|c|c|c|}
\hline$E_{11}, \mathrm{GPa}$ & $E_{22}, \mathrm{GPa}$ & $G_{12}, \mathrm{GPa}$ & $v_{12}$ & $\sigma_{11}, \mathrm{MPa}$ & $\sigma_{22}, \mathrm{MPa}$ \\
\hline 64 & 64 & 4,1 & 0,3 & 810 & 810 \\
\hline
\end{tabular}

A model of an orthotropic material *MAT_054 with fracture was used to describe the mechanical behaviour of the composite. In plane stress, the strain is given in terms of the stress as

$$
\varepsilon_{11}=\frac{1}{E_{11}}\left(\sigma_{1}-v_{12} \sigma_{2}\right)
$$

$$
\begin{aligned}
& \varepsilon_{22}=\frac{1}{E_{22}}\left(\sigma_{2}-v_{21} \sigma_{1}\right), \\
& 2 \varepsilon_{12}=\frac{1}{G_{12}} \tau_{12}+\alpha \tau_{12}^{3} .
\end{aligned}
$$

Usually, $\alpha$ is defined by material shear stress-strain measurements, $v_{12}=v_{12}$. In the present work, it was assumed that $\alpha=0$. A detailed description of this material model could be found in [76, 79].

Earlier, several assumptions have been formulated that require verification:

1. energy absorbed in the tensile failure of the primary yarns (the yarns directly below the projectile), the energy absorbed in the elastic deformation of the secondary yarns (the yarns that are not under the projectile) and the energy absorbed in the form of kinetic energy of the moving cone are the main mechanisms of the projectile kinetic energy dissipation in composites;

2. delaminations accounting in the model is necessary, first of all, to obtain an adequate deformation and fracture pattern;

3. parameters of the material deformation and fracture model, FE size, some equivalent layers should be defined through experimental and numerical verification.

To verify these assumptions, only ultimate tensile stresses on warp and weft directions were specified $\left(X_{\mathrm{T}}=Y_{\mathrm{T}}=810 \mathrm{MPa}\right)$ in the model. In this case, fracture criteria are given as follows:

$$
\begin{aligned}
& \sigma_{11}>0 \text { then }\left(\frac{\sigma_{11}}{X_{T}}-1\right)\left\{\begin{array}{l}
\geq 0 \text { failed, } \\
<0 \text { elastic, }
\end{array}\right. \\
& \sigma_{22}>0 \text { then }\left(\frac{\sigma_{22}}{Y_{T}}-1\right)\left\{\begin{array}{l}
\geq 0 \text { failed, } \\
<0 \text { elastic. }
\end{array}\right.
\end{aligned}
$$

When failure has occurred, elastic constant of composite layers $\left(E_{11}, E_{22}, G_{12}, v_{12}\right)$ are set to zero. Maximum strains for fibre tension in warp/weft directions $\varepsilon_{11}^{F}, \varepsilon_{22}^{F}$ were defined during preliminary simulations $\left(\varepsilon_{11}^{F}=\varepsilon_{22}^{F}=0,016\right)$. The layer in the element is completely removed after the maximum tensile strains in the fibre direction is reached. These parameters were used in all simulations to understand the necessity of consideration of changes in the properties of the composite at high-strain rates.

The contact between the projectile and composite layers was specified using *CONTACT_ERODING_SURFACE_ TO_SURFACE command.

Contact *CONTACT_AUTOMATIC_SURFACE_TO_ SURFACE_TIEBREAK with OPTION=6 was used between layers for delamination modelling. Maximum normal and shear stresses were equal (NFLS=SFLS=75 MPa). Maximum contact opening parameter PARAM was 0.03 $\mathrm{mm}$. When the distance is equal to PARAM, the damage is fully developed after that bonded interface failure occurs and behaves as a surface-to-surface contact. 


\section{Results of numerical simulations and discussion}

In the following, the results obtained for the steel ball impact simulations are discussed. Fig. 5 shows the deformation states (cross-sectional view) of the model configuration with 12 equivalent layers and with a $\mathrm{FE}$ size of $3 \mathrm{~mm}$ that was impacted at the velocity of $90.5 \mathrm{~m} / \mathrm{s}$. It is seen that the model predicted maximum delaminations close to the backside of the panel that is correlated with results reported in work [61].

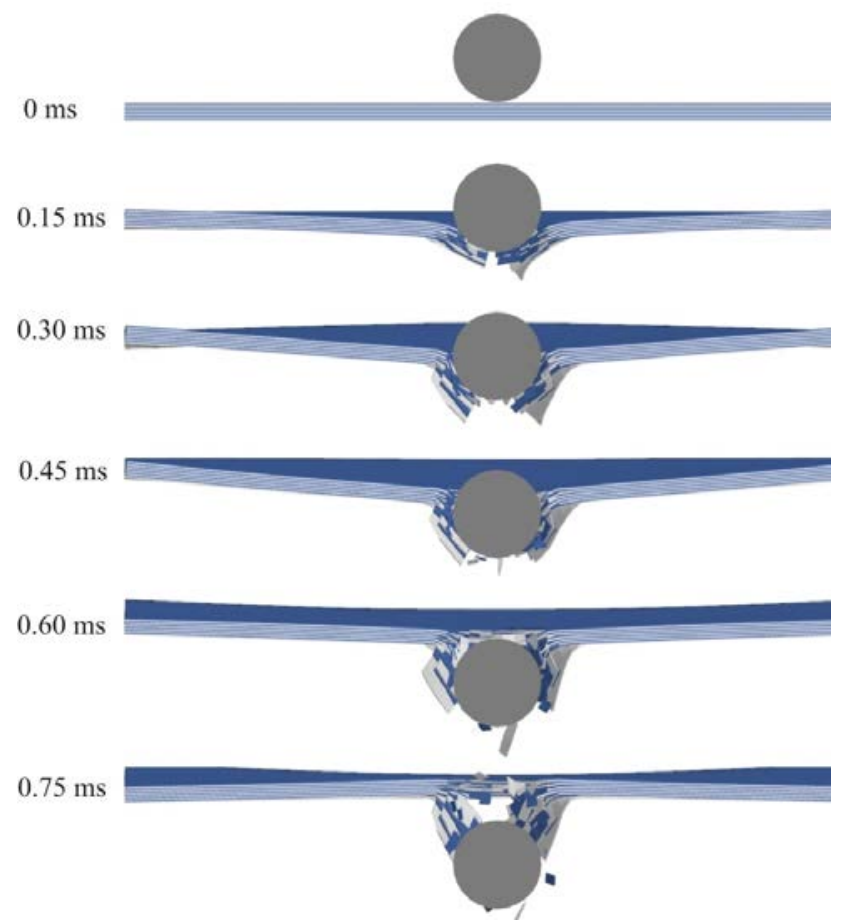

Fig. 5. A sectional view of the deformed shape of the composite panel model at different time steps

The damage patterns on the bottom side of the models after penetration for the models with FE sizes of $2 \mathrm{~mm}$ and $3 \mathrm{~mm}$ looked like a through-hole with a cruciform crack oriented parallel to the sides of the panel. This fact is in a good agreement with experimental results presented in [48] (Fig. 6).

The damage patterns for the models with FE size of $4 \mathrm{~mm}$ were more irregular due to the large size of the finite elements in comparison with other models (Fig. 7).

The residual projectile velocity after perforation indicates the amount of the kinetic energy absorbed by the target, and it is one of the critical parameters for the model validation. During the simulations, residual projectile velocity was defined and compared with experimental data [48] for all models (Table 2).

First, it should be noted that the process of interaction of a high-speed projectile with a target is mostly random which leads to significant variations in experimental data. This fact is especially noticeable near the ballistic limit when both complete stop and penetration are possible with the same initial projectile velocity. Thus, it is more correct to use for verification of the model, not single experimental points, but a ballistic curve obtained by fitting of these. Unfortunately, the authors in [48] did not provide enough experimental data to obtain a ballistic curve, and it is impossible to assess the experimental data scattering.
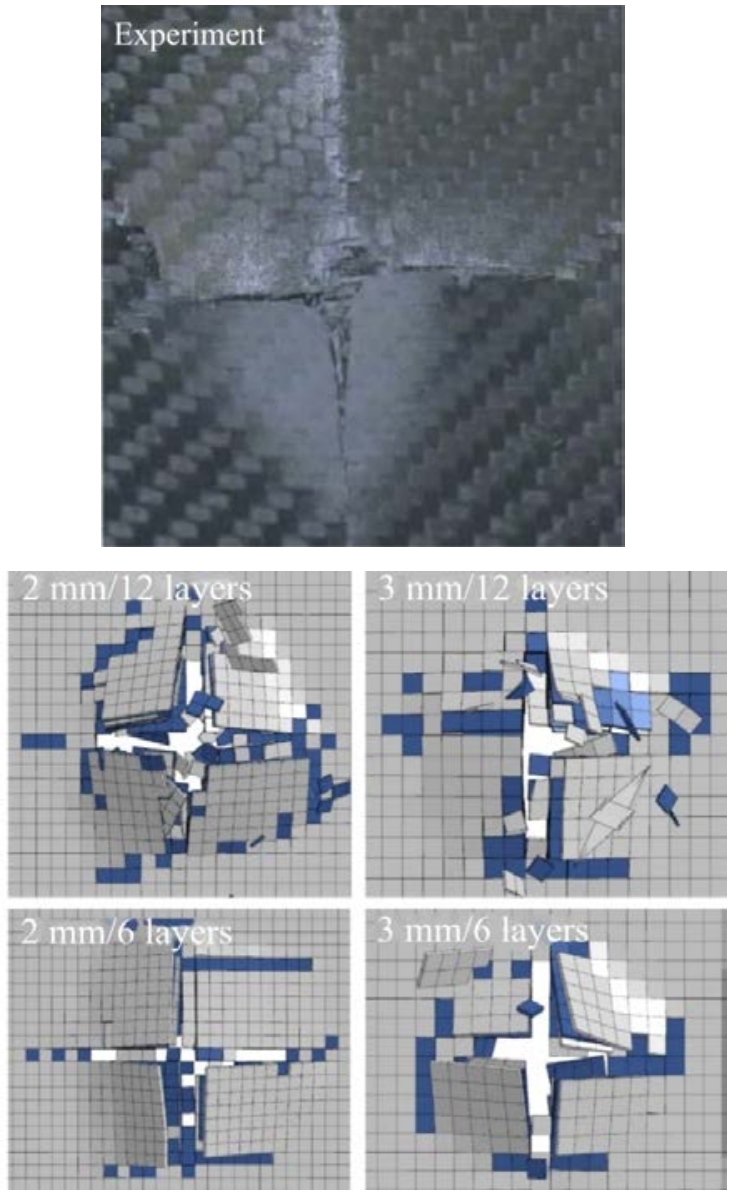

Fig. 6. Comparison of the damage patterns on the bottom side of the models with experimentally obtained results [48] (initial projectile velocity of $90.5 \mathrm{~m} / \mathrm{s}$ )
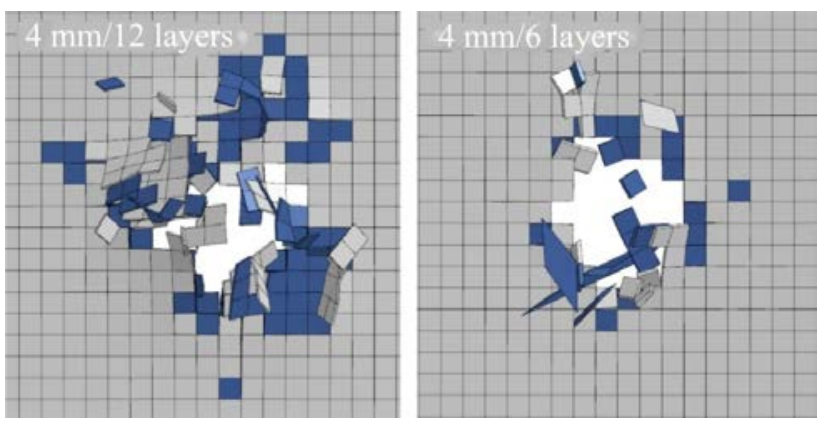

Fig. 7. Damage patterns on the bottom side of the models with FE size of $4 \mathrm{~mm}$ for the initial projectile velocity of $90.5 \mathrm{~m} / \mathrm{s}$

A direct comparison of the results of calculations with experimental data shows that none of the models provides an accurate prediction over the entire velocity range considered. The model with 12 equivalent layers and FE size of 2 $\mathrm{mm}$ predicts the residual projectile velocity at its initial speeds of $100.5 \mathrm{~m} / \mathrm{s}$ and $90.5 \mathrm{~m} / \mathrm{s}$ with an error not exceeding $1 \mathrm{~m} / \mathrm{s}$ but predicts an underestimated energy absorption close to ballistic to the limit. 
Table 2 formed at an initial impact velocity of $90.5 \mathrm{~m} / \mathrm{s}$ for the mod-

Numerically obtained residual velocities of the projectile for models with different finite element size/number of equivalent layers

\begin{tabular}{|c|c|c|c|c|c|c|c|}
\hline $\begin{array}{c}\text { Initial } \\
\text { projec- } \\
\text { tile } \\
\text { velocity } \\
(\mathrm{m} / \mathrm{s})\end{array}$ & $\begin{array}{c}\mathbf{7} \text { Residual projectile velocity (m/s) } \\
2 \mathrm{~mm} / \\
12 \text { lay- } \\
\text { ers }\end{array}$ & $\begin{array}{c}2 \mathrm{~mm} / \\
6 \text { lay- } \\
\text { ers }\end{array}$ & $\begin{array}{c}3 \mathrm{~mm} / \\
12 \text { lay- } \\
\text { ers }\end{array}$ & $\begin{array}{c}3 \mathrm{~mm} / \\
6 \text { lay- } \\
\text { ers }\end{array}$ & $\begin{array}{c}4 \mathrm{~mm} / \\
12 \text { lay- } \\
\text { ers }\end{array}$ & $\begin{array}{c}4 \mathrm{~mm} / \\
6 \text { lay } \\
\text { ers }\end{array}$ & $\begin{array}{c}\text { Experi- } \\
\text { mental } \\
{[48]}\end{array}$ \\
\hline 110.5 & 84.3 & 86.2 & 76.3 & 81.5 & 72.2 & 86.9 & 85 \\
\hline 90.5 & 55.9 & 62.1 & 41.9 & 44.9 & 23.7 & 57.7 & 55 \\
\hline 84.5 & 48.1 & 53.2 & 23.8 & 29.1 & 26.3 & 49 & 29 \\
\hline 75.5 & 26 & 32.9 & 0 & 0 & 0 & 0 & 0 \\
\hline
\end{tabular}

The residual velocities obtained on the model with six equivalent layers and a $\mathrm{FE}$ size of $3 \mathrm{~mm}$ are close to the experimental ones near the ballistic limit. For the initial projectile velocities of $100.5 \mathrm{~m} / \mathrm{s}$ and $90.5 \mathrm{~m} / \mathrm{s}$, this model is a bit overpredicted. The results obtained on models with 12 equivalent layers indicate that the larger the size of the final elements, the higher the value of the absorbed kinetic energy of the projectile in the simulation. The situation is similar for models with six equivalent layers and FE sizes of 2 $\mathrm{mm}$ and $3 \mathrm{~mm}$. A model with a FE size of $4 \mathrm{~mm}$ showed unstable results both according to the prediction of the fracture pattern and the residual velocities. The most likely reason is that the size of the finite elements is too large compared to the projectile. In general, the obtained results confirm that it is challenging to choose the model parameters without information about the experimental points scattering. It is also noticeable that all models predict the residual velocity of $280 \pm 2 \mathrm{~m} / \mathrm{s}$ for the initial projectile velocity of $300 \mathrm{~m} / \mathrm{s}$. It means that data on the mechanical behaviour of specimens near the ballistic limit has the highest importance for the model calibration and it is enough to have only a few experimental points at the velocities well above the ballistic limit.

The damaged area size is another parameter that can be used to verify numerical models of composite materials under the impact. In this work, the nominal damaged area of the backside of the plate (product of damage sizes in warp and weft directions) was used to assess the damage pattern. Numerically obtained nominal damaged areas and the experimental result obtained for the projectile velocity of $90.5 \mathrm{~m} / \mathrm{s}$ are presented in Fig. 7. All models except one with 12 equivalent layers and finite elements size of $4 \mathrm{~mm}$ demonstrated behaviour that agree with published results [80]. Maximum damages of the composite panel are predicted close to ballistic limit velocity; for higher velocities, the damaged area reduces and then becomes almost constant. Fig. 8 demonstrates that the difference between models predictions could be more than three times depending on the initial projectile velocity. Comparison of numerical results with experimental data for specimen impacted at the velocity of $90.5 \mathrm{~m} / \mathrm{c}$ shows that neither models do not predict the damaged area correctly and the error is more than $100 \%$.

To estimate the effect of interlayer contact parameters on the calculation results, additional calculations were perel with six equivalent layers and the $\mathrm{FE}$ size of $3 \mathrm{~mm}$. The considered combinations of parameters of interlayer contacts, the obtained residual speeds and the values of the nominal damaged area are presented in Table 3. It can be seen that for PARAM values of 0.01-0.02 mm and two levels of strength, the residual projectile velocities vary insignificantly: the difference between the maximum and minimum values was about $5 \mathrm{~m} / \mathrm{s}$. At the same time, the nominal damaged area varies more than twice. With the parameters NFLS $=$ SFLS $=100 \mathrm{MPa}$, the model predicts the stop of the projectile and a very high damaged area that is inconsistent with the experiments. The obtained data show that the parameters of the contact algorithm make it possible to control the calculated fracture pattern even within a single combination of the FE size and the number of equivalent layers over a wide range.

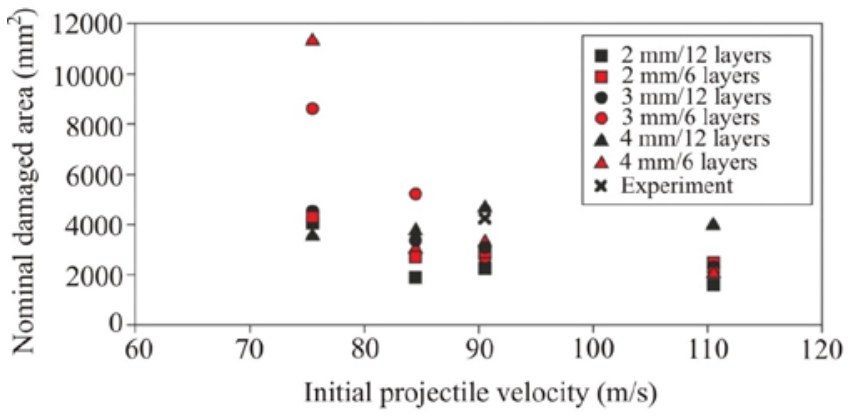

Fig. 8. The nominal value of damaged area on the back side of the models vs initial projectile velocity

Table 3

Contact parameters, residual projectile velocities and nominal damaged areas for the model with six equivalent layers and FE size of $3 \mathrm{~mm}$ impacted at the velocity of $90.5 \mathrm{~m} / \mathrm{s}$

\begin{tabular}{|c|c|c|c|c|}
\hline \multirow{2}{*}{$\begin{array}{c}\text { Contact } \\
\text { parameters } \\
\text { combination }\end{array}$} & $\begin{array}{c}\text { Contact Parameters } \\
\text { NFL=SFLS } \\
(\mathrm{MPa})\end{array}$ & $\begin{array}{c}\text { PARAM } \\
(\mathrm{mm})\end{array}$ & $\begin{array}{c}\text { Residual } \\
\text { projectile } \\
\text { velocity } \\
(\mathrm{m} / \mathrm{s})\end{array}$ & $\begin{array}{c}\text { Nominal } \\
\text { damaged } \\
\text { area }\left(\mathrm{mm}^{2}\right)\end{array}$ \\
\hline 1 & 50 & 0,01 & 46,0 & 6888 \\
\hline 2 & 50 & 0,02 & 43,9 & 6160 \\
\hline 3 & 50 & 0,03 & 49,2 & 3808 \\
\hline 4 & 75 & 0,01 & 45,8 & 2740 \\
\hline 5 & 75 & 0,02 & 43,8 & 2800 \\
\hline 6 & 75 & 0,03 & 44,9 & 2668 \\
\hline 7 & 100 & 0,01 & 0 & 16632 \\
\hline 8 & 100 & 0,02 & 0 & 14664 \\
\hline 9 & 100 & 0,03 & 0 & 19564 \\
\hline \multicolumn{5}{|l|}{} \\
\hline Experiment & - & - & 55 & 4420 \\
\hline
\end{tabular}

On the one hand, this allows us to achieve the best fit with the experimental data, but on the other hand, the selection of the parameters of the contact algorithm for each model will require appropriate computational studies. It should be noted that it would be incorrect to verify contact algorithms by individual points, as in the case of the residual projectile velocities. It is necessary to have experimental data about the scattering of the damaged area. 


\section{Basic recommendations on high-velocity composite impact modelling}

The obtained results allow us to conclude that when modelling the mechanical behaviour of composite structures during high-velocity impact, we cannot talk only about the verification of the parameters of deformation and fracture material model. A size of finite elements, some equivalent layers, interlayer interaction algorithms also significantly affects the calculation results. It is impossible to determine all parameters of the model only by static and dynamic tests of specimens. An extensive and multi-stage experimental verification of the model is required before it allows to predict the behaviour of the composite element under impact correctly. It is noteworthy that a similar approach is already successfully used for metals by P.A. Mossakovskii et al. to predict the destruction of the GTE during fan blade-out events [81].

For composite structures, it is impossible to develop a standard procedure of the model verification with a known number of specimens, test types and design cases because in each case the materials, loading conditions, and requirements for the calculation results will differ. However, it is possible to identify the main stages of verification of the computational model parameters:

1. The static and dynamic test of composite specimens on tension, compression and shear.

2. Ballistic tests of the composite plates with the projectiles of different shape and size.

3. Primary identification of the numerical model parameters using the results of static, dynamic and ballistic tests.

4. Additional experimental studies of the composite plates subjected to oblique or edge-on high-velocity impact.

5. The refinement of the model parameters using results of oblique or edge-on high-velocity impact tests.

6. Impact tests of the structurally similar composite specimens.

7. The refinement of the model parameters using results of the impact tests of structurally similar composite specimens.

Only then, we can say that the computational model will have a predictive ability and start to model the real structure.

The results of numerical calculations confirmed the possibility of using relatively simple fracture models and contact algorithms in the calculations of the impact loading of CFRP. In the cases when there is a limited list of experimental data, this approach may be a right choice.

Using the ballistic curve allows reducing the influence of the experimental point scattering on the results of the model verification. Classical Lambert-Jonas equation [82] is one of the most common dependencies for ballistic curve approximation:

$$
V_{\mathrm{r}}=\left\{\begin{array}{l}
0 \text { if } V_{\mathrm{i}}<V_{50}, \\
A \cdot\left(V_{\mathrm{i}}^{k}-V_{50}^{k}\right)^{1 / k} \text { if } V_{\mathrm{i}} \geq V_{50},
\end{array}\right.
$$

where $A, V_{50}$ and $k$ are three regression parameters. $V_{\mathrm{r}}$ and $V_{\mathrm{i}}$ are the residual and initial velocities of the projectile, respectively. $V_{50}$ defines incident impact velocity at which there is $50 \%$ probability of partial penetration and $50 \%$ probability of perforation [0], and it is close to ballistic limit velocity $V_{\mathrm{BL}}$ (maximum initial projectile velocity which does not cause full perforation). In engineering practice, it can be assumed that $V_{\mathrm{BL}} \approx V_{50}$.

The size of the finite elements is just as important a part of the computational model, as well as the material properties, interlayer contacts. The choice of the FE size is required a significant amount of computational studies. Reducing the FE size in the simulations of composite structures under impact does not mean an increase of the calculations accuracy. In cases when the FE size in the ply-level model is smaller than the size of the representative unit cell of the material, this can lead to errors in determining the damaged area. This also should be taken into account during the planning of the ballistic tests for the model verification.

In this work, the 8-nodes thick shell (tshell) elements were used to simulate the high-velocity impact loading of the composites. These elements, in contrast to standard shell elements, consider transversal composite stiffness and allow to use advanced contact algorithms. Composite parts of prospective jet engines will have a thickness of several tens of millimetres and thick shell finite elements look promising for further studies.

\section{Conclusion}

The results of the literature review and the performed calculations show that numerical simulations are a powerful tool in the design of composite structural elements, but they are not a substitute for experimental research. Certainly, numerical simulation minimises the number of expensive full-sized tests, but it will require a sufficiently large amount of testing samples of materials and structurally similar samples of various configurations and under various conditions for verification of computational models. Also, extensive computational studies are required on the selection of parameters such as the size of finite elements, the number of equivalent layers, the parameters of the contact algorithm, the parameters of the models of deformation and fracture of materials.

It should be noted in this paper that only standard layered composites were considered. At the same time, composites with three-dimensional reinforcement are increasingly used in the aerospace industry due to the high resistance to interlayer delamination. For such materials, the situation when modelling is aggravated by the presence of reinforcement in the z-direction, which must be taken into account. Extensive experimental and numerical researches are needed in this direction.

\section{Acknowledgement}

This work was financially supported by the Russian Science Foundation (project No. 18-19-00377). 


\section{References}

1. Karelin O.O., Koltyrina K.Y. Employment of composite materials in aero-engine manufacturing. Bulletin of P.A. Solovyov Rybinsk State Aviation Technical University. 2015, no. 2 (35), pp. 53-59.

2. Karimbaev T.D. CF composite fan rotor blading for perspective engines. Engine. 2011, no. 6. pp. 1-6.

3. Rubcov S.M. Primenenie sovremennyh polimernyh kompozicionnyh materialov v ehlementah i uzlah gazoturbinnyh aviacionnyh dvigatelej: dissertaciya na soiskanie uchenoj stepeni k.t.n: 05.02.01, Perm' 2009, 140p.

4. Anoshkin A.N., Zuiko V.Yu., Shipunov G.S., Tretyakov A.A. Technologies and problems of composite materials mechanics for production of outlet guide vane for aircraft jet engine. PNRPU Mechanics Bulletin. 2014, no. 4, pp. 5-44. DOI: 10.15593/perm.mech/2014.4.01

5. Grinev M.A., Anoshkin A.N., Pisarev P.V., Zuiko V.Yu., Shipunov G.S. CAD/CAE modelling of mechanical behavior of composite outlet guide vane for aircraft jet engine. PNRPU Mechanics Bulletin. 2015, no. 3, pp. 38-51. DOI:10.15593/perm.mech/2015.3.04

6. Grinev M.A., Anoshkin A.N., Pisarev P.V., Zuiko V.Yu., Shipunov G.S. Stress-strain analysis and strength prediction of composite outlet guide vane for aircraft jet engine. PNRPU Mechanics Bulletin. 2015, no. 4, pp. 293-307. DOI:10.15593/perm.mech/2015.4.17

7. Reddy J. Mechanics of laminated composite plates and shells - theory and analysis. 2nd ed. CRC Press; 2003.

8. Shipunov G.S. Raschetno-ehksperimental'naya ocenka staticheskoj prochnosti lopatki spryamlyayushchego apparata iz polimernyh kompozicionnyh materialov: dissertaciya na soiskanie uchenoj stepeni k.t.n: 01.02.04 / Perm' 2016. - 136 s.

9. Grujicic M., Pandurangan B., Koudela K.L., Cheeseman B. A computational analysis of the ballistic performance of lightweight hybrid composite armors. Applied Surface Science. 2006 , vol. 253, pp. 730-745.

10. M. Grujicic, G. Arakere, T. He, W.C. Bell, P.S. Glomski, B.A. Cheeseman. Multi-scale ballistic material modeling of crossplied compliant composites. Composites Part B: Engineering. 2009, vol. 40, iss. 6, pp. 468-482.

11. Dimitrienko Yu.I., Belenovskaya Yu.V., Aniskovich V.A. Numerical simulation of shock-wave deformation of flexible armored composite materials. Science and Education. 2013, vol. 12, pp. 471-490.

12. Dimitrienko Yu.I., Dimitrienko I.D. Modelirovanie processov probivaniya kompozitnyh tekstil'nyh pregrad. Inzhenernyj zhurnal: Nauka i Innovacii. 2015, no. 4, pp. 1-23.

13. Zhang C., Curiel-Sosa J.L., Duodu E.A.. Finite element analysis of the damage mechanism of 3D braided composites under high-velocity impact. Journal of Materials Science. 2017, vol. 52, pp. 4658-4674.

14. Li Z., Sun B., Gu B. FEM simulation of 3D angleinterlock woven composite under ballistic impact from unit cell approach. Computational Materials Science. 2010, vol. 49, pp. 171-183.

15. Sun B., Liu Y., Gu B. A unit cell approach of finite element calculation of ballistic impact damage of 3-D orthogonal woven composite. Composites Part B: Engineering. 2009, vol. 40, pp. 552-560.

16. Loikkanen M., Praveen G., Powell D. Simulation of Ballistic Impact on Composite Panels. 10th International LS-DYNA Conference. 2008, pp. 1-9.
17. Liu L., He Z., Niu D., Xing J., Hong W. Containment capability of 2D triaxial braided tape wound composite casing for aero-engine. Polymer Composites. 2016, vol. 37, pp. 22272242.

18. Aymerich F., Dore F., Priolo P. Simulation of multiple delaminations in impacted cross-ply laminates using a finite element model based on cohesive interface elements. Composites Science and Technology. 2009, vol. 69, pp.1699-1709.

19. Heimbs S., Bergmann T., Schueler D., Toso-Pentecôte N. High velocity impact on preloaded composite plates. Composite Structures. 2014, vol. 111, pp. 158-168.

20. May M. Numerical evaluation of cohesive zone models for modeling impact induced delamination in composite materials. Composite Structures. 2015, vol. 133, pp. 16-21.

21. Varas D., Artero-Guerrero J.A., Pernas-Sánchez J., López-Puente J. Analysis of high velocity impacts of steel cylinders on thin carbon/epoxy woven laminates. Composite Structures. 2013, vol. 95, pp. 623-629.

22. Pernas-Sanchez J., Artero-Guerrero J.A., L'opez-Puente J., Varas D. Numerical methodology to analyze the ice impact threat: application to composite structures. Materials \& Design. 2018, vol. 141, pp. 350-360.

23. Pernas-Sánchez J., Artero-Guerrero J.A., Zahr Viñuela J., Varas D., López-Puente J. Numerical analysis of high velocity impacts on unidirectional laminates. Composite Structures. 2014, vol. 107, pp. 629-634.

24. Luo H., Yan Y., Zhang T., He Z., Wang S. Progressive failure numerical simulation and experimental verification of carbon-fiber composite corrugated beams under dynamic impact. Polymer Testing. 2017, vol. 63, pp. 12-24.

25. Turon A., Davila C.G., Camanho P.P., Costa J. An Engineering Solution for solving Mesh Size Effects in the Simulation of Delamination with Cohesive Zone Models.

26. S.A. Muflahi, G. Mohamed, S.R. Hallett. Investigation of Delamination Modeling Capabilities for Thin Composite Structures in LS-DYNA. 13th International LS-DYNA Conference. 2014, pp. 1-14.

27. Ahn J.-H., Nguyen K.-H., Park Y.-B., Kweon J.-H., Choi J.-H. A Numerical Study of the High-Velocity Impact Response of a Composite Laminate Using LS-DYNA. IJASS. 2010, vol. 11, no. 3, pp. 221-226.

28. Menna C., Asprone D., Caprino G., Lopresto V., Prota A. Numerical simulation of impact tests on GFRP composite laminates. International Journal of Impact Engineering. 2011, vol. 38, pp. 677-685.

29. Sevkat E. Experimental and numerical approaches for estimating ballistic limit velocities of woven composite beams. International Journal of Impact Engineering. 2012, vol. 45, pp. 16-27.

30. Zhang X., Liu T., He N., Jia G. Investigation of two finite element modelling approaches for ballistic impact response of composite laminates. International Journal of Crashworthiness. 2016. DOI: 10.1080/13588265.2016.1270495

31. Chocron S., Nicholls A.E., Brill A., Malka A., Namir T., Havazelet D., H. van der Werff, Heisserer U., Walker J.D. Modeling unidirectional composites by bundling fibers into strips with experimental determination of shear and compression properties at high pressures. Composites Science and Technology. 2014, vol. 101, pp. 32-40.

32. Dogan F., Hadavinia H., Donchev T., Bhonge P.S. Delamination of impacted composite structures by cohesive zone 
interface elements and tiebreak contact. Cent. Eur. J. Eng. 2012, vol. 2(4), pp. 612-626. DOI: 10.2478/s13531-012-0018-0

33. Gopinath G., Zheng J.Q., Batra R.C. Effect of matrix on ballistic performance of soft body armor. Composite Structures. 2012, vol. 94, pp. 2690-2696.

34. Kudryavtsev O.A., Sapozhnikov S.B. Yarn-level modelling of woven and unidirectional thermoplastic composite materials under ballistic impact. PNRPU Mechanics Bulletin. 2016, no. 3, pp. 108-119.

35. Zhikharev M.V., Sapozhnikov S.B. Two-scale modeling of high-velocity fragment GFRP penetration for assessment of ballistic limit. International Journal of Impact Engineering. 2017, vol.101, pp. 42-48.

36. Ha-Minh C., Imad A., Boussu F., Kanit T.. Experimental and numerical investigation of a 3D woven fabric subjected to a ballistic impact. International Journal of Impact Engineering. 2016, vol. 88, pp. 91-101.

37. Chu T.-L., Ha-Minh C., Imad A. Analysis of local and global localizations on the failure phenomenon of 3D interlock woven fabrics under ballistic impact. Composite Structures. 2017, vol. 159, pp. 267-277.

38. Turnera P., Liua T., Zeng X., Brown K. Threedimensional woven carbon fibre polymer composite beams and plates under ballistic impact. Composite Structures. 2018, vol. 185, pp. 483-495.

39. Ghosh R., De S. Z-fiber influence on high speed penetration of 3D orthogonal woven fiber composites. Mechanics of Materials. 2014, vol. 68, pp. 147-163.

40. Luan K., Sun B., Gu B. Ballistic impact damages of 3-D angle-interlock woven composites based on high strain rate constitutive equation of fiber tows. International Journal of Impact Engineering. 2013, vol. 57, pp. 145-158.

41. Muñoz R., Martínez-Hergueta F., Gálvez F., González C., LLorca J. Ballistic performance of hybrid 3D woven composites: Experiments and simulations. Composite Structures. 2015, vol. 127, pp. 141-151.

42. Nilakantan G. Filament-level modeling of Kevlar KM2 yarns for ballistic impact studies. Composite Structures. 2013, vol. 104, p. 1-13.

43. Segala D.B., Cavallaro P.V. Numerical investigation of energy absorption mechanisms in unidirectional composites subjected to dynamic loading events. Computational Materials Science. 2014, vol. 81, pp. 303-312.

44. Grujicic M., Arakere G., He T., Bell W.C., Cheeseman B.A., Yen C.-F., Scott B. A ballistic material model for cross-plied unidirectional ultra-high molecular-weight polyethylene fiberreinforced armor-grade composites. Materials Science and Engineering: A. 2008, vol. 498 (1-2), pp. 231-241.

45. Schwab M., Pettermann H.E. Modelling and simulation of damage and failure in large composite components subjected to impact loads. Composite Structures. 2016, vol. 158, pp. 208-216.

46. Schwab M., Todt M., Pettermann H.E. A multiscale approach for modelling impact on woven composites under consideration of the fabric topology. Journal of Composite Materials. 2018, vol 52, is. 21, pp. 2859-2874.

47. Bresciani L.M., Manes A., Ruggiero A., Iannitti G., Giglio M. Experimental tests and numerical modelling of ballistic impacts against Kevlar 29 plain-woven fabrics with an epoxy matrix: Macrohomogeneous and Meso-heterogeneous approaches. Composites Part B: Engineering. 2016, vol. 88, pp. 114-130.

48. Nikhamkin M.Sh., Voronov L.V., Gladkiy I.L. Experimental investigation of high-speed impact damage of carbon for aviation engines parts. Composite Materials Constructions. 2015, no. 4 (140), pp. 74-80.

49. Morye S.S., Hine P.J., Duckett R.A., Carr D.J., Ward I.M. Modelling of the energy absorption by polymer composites upon ballistic impact. Composites Science and Technology. 2000, vol. 60, iss. 14, pp. 2631-2642.

50. Naik N.K., Shrirao P., Reddy B.C.K. Ballistic impact behaviour of woven fabric composites: Parametric studies. Materials Science and Engineering A. 2005, vol. 412, pp. 104-116.

51. Naik N.K., Doshi A.V. Ballistic Impact Behavior of Thick Composites: Analytical Formulation. AIAA JOURNAL. 2005, vol. 43, no. 7, pp 1525-1536.

52. Naik N.K., Shrirao P., Reddy B.C.K. Ballistic impact behaviour of woven fabric composites: Formulation. International Journal of Impact Engineering. 2006, vol. 32, 2006, pp. 15211552.

53. Naik N.K., Doshi A.V. Ballistic impact behaviour of thick composites: Parametric studies. Composite Structures. 2008, vol. 82, pp. 447-464.

54. Udatha P., Kumar Ch.V.S., Nair N.S., Naik N.K. High velocity impact performance of three-dimensional woven composites. The Journal of Strain Analysis for Engineering Design. 2012, vol. 47(7), pp. 419-431.

55. Shaktivesh, Nair N.S., Kumar Ch.V.S., Naik N.K. Ballistic impact performance of composite targets. Materials \& Design. 2013, vol. 51, pp. 833-846.

56. Pandya K.S., Kumar Ch.V.S., Nair N.S., Patil P.S., Naik N.K. Analytical and experimental studies on ballistic impact behavior of 2D woven fabric composites. International Journal of Damage Mechanics. 2014, pp. 1-41. DOI: 10.1177/1056789514531440.

57. Patil P.S., Naik N.K.. Ballistic impact performance of spaced multilayered and monolithic composite targets: Analytical and experimental studies. International Journal of Damage Mechanics. 2017, pp. 1-28. DOI: 10.1177/1056789517732376.

58. Buitrago B.L., García-Castillo S.K., Barbero E. Influence of shear plugging in the energy absorbed by thin carbon-fibre laminates subjected to high-velocity impacts. Composites Part B: Engineering. 2013, vol. 49, pp. 86-92.

59. Alonso L., Navarro C., García-Castillo S.K. Analytical models for the perforation of thick and thin thickness wovenlaminates subjected to high-velocity impact. Composites Part B: Engineering. 2018, vol. 143, pp. 292-300.

60. Xie W., Zhang W., Kuang N., Li D., Huang W., Gao Y., Ye N., Guo L., Ren P. Experimental investigation of normal and oblique impacts on CFRPs by high velocity steel sphere. Composites Part B: Engineering. 2016, vol. 99, pp. 483-493.

61. Yashiro S., Ogi K., Nakamura T., Yoshimura A. Characterization of high-velocity impact damage in CFRP laminates: Part I - Experiment. Composites: Part A. 2013, vol. 48, pp. 93100.

62. Pernas-Sánchez J., Artero-Guerrero J.A., Varas D., López-Puente J. Experimental analysis of normal and oblique high velocity impacts on carbon/epoxy tape laminates. Composites: Part A. 2014, vol. 60, pp. 24-31.

63. Al-Mosawe A., Al-Mahaidi R., Zhao X.L. Engineering properties of CFRP laminate under high strain rates. Composite Structures. 2017, vol. 180, pp. 9-15.

64. Al-Zubaidy H., Zhao X.L., Al-Mahaidi R.. Mechanical characterization of the dynamic tensile properties of CFRP sheet and adhesive at medium strain rates. Composite Structures. 2013, vol. 96, pp. 153-164. 
65. Adams D., Adams L. Tensile impact tests of AS4/3501-6 and S2/3501-6 unidirectional composites and the 3501-6 epoxy matrix. Journal of Composite Materials. 1990, vol. 24, pp. 256-268.

66. Gómez-del Río T., Barbero E., Zaera R., Navarro C. Dynamic tensile behaviour at low temperature of CFRP using a split Hopkinson pressure bar. Composite Science and Technology. 2005, vol. 65, pp. 61-71.

67. Hou J.P., Ruiz C. Measurement of the properties of woven CFRP T300/914 at different strain rates. Composite Science and Technology. 2000, vol. 60, pp. 2829-2834.

68. Lifshitz J.M., Leber H. Response of fiber-reinforced polymers to high strain-rate loading in interlaminar tension and combined tension/shear. Composite Science and Technology. 1998, vol. 58, pp. 987-996.

69. Wang W., Makarov G., Shenoi R.A. An analytical model for assessing strain rate sensitivity of unidirectional composite laminates. Composite Structures. 2005, vol. 69, pp. 45-54.

70. Zhou Y.X., Dai Zh.Q., Xia Y.M. Tensile mechanical behavior of T300 and M40J fiber bundles at different strain rate. Journal of Material Sciences. 2001, vol. 36(4), pp. 919-922.

71. Zhou Y.X., Wang Y., Xia Y.M. Experimental study on tensile behavior of carbon fiber and carbon fiber reinforced aluminum at different strain rate. Applied Composite Materials. 2007, vol. 14(1), pp. 17-31.

72. Hou Y., Hu H., Sun B., Gu B. Strain rate effects on tensile failure of 3-D angle-interlock woven carbon fabric. Materials \& Design, 2013, vol. 46, pp. 857-866.

73. Taniguchi N., Nishiwaki T., Kawada H. Tensile strength of unidirectional CFRP laminate under high strain rate. Advanced Composite Materials. 2007, vol. 16, pp. 167-80.

74. Gama B.A., Gillespie Jr J.W. Finite element modeling of impact, damage evolution and penetration of thick-section com- posites. International Journal of Impact Engineering. 2011, vol. 38, pp. 181-197.

75. Bower A.F. Applied Mechanics of Solids. CRC Press, 2009. 820p.

76. LS-DYNA theoretical manual / compiled by John O. Hollquist. LSTC, 2006, 680 p.

77. Kostenetskiy P.S., Safonov A.Y. SUSU Supercomputer Resources. CEUR Workshop Proceedings. 2016, V. 1576, pp. 561-573.

78. PREPREGA CARBON fiber GRADE VKU-39 [Electronic resource] /. - Electron. text messages. - Access mode: https://catalog.viam.ru/catalog/vku_39_/prepreg-ugleplastikamarki-vku-39/, free. - Weak and srednekaloriynye PCM structures(folds, landing gear, flaps, elements of the tail)

79. Feraboli P., Wade B., Deleo F., Rassaian M., Higgins M., Byar A. LS-DYNA MAT54 modeling of the axial crushing of a composite tape sinusoidal specimen. Composites Part A: Applied Science and Manufacturing. 2011,vol.42, iss, 11, pp. 1809-1825.

80. Zhikharev M.V., Sapozhnikov S.B. Ballistic damages of GFRP and their repairs us ultrasound matrix impregnation. PNRPU Mechanics Bulletin. 2015, no. 4, pp. 94-109.

81. Vedeneev V.V., Kolotnikov M.E., Mossakovskii P.A., Kostyreva L.A., Abdukhakimov F.A., Makarov P.V., Pyhalov A.A., Dudaev M.A. A Comprehensive Solution of the Problems of Ensuring the Strength of Gas Turbine Engine Compressor at the Design Stage. 2018 IOP Conf. Ser.: Mater. Sci. Eng. 302012079.

82. Lambert J.P., Jonas G.H. Towards standardization in terminal ballistics testing: velocity representation. BRL Report no. 1852. Aberdeen Proving Ground, MD: U.S. Army Ballistic Research Laboratories; 1976. p. 51.

83. Bhatnagar A. Lightweight ballistic composites - military and law-enforcement applications. Cambridge: Woodhead Publishing Ltd., 2006. 482 p. 